\title{
CMIP5 model simulations of Ethiopian Kiremt-season precipitation: current climate and future changes
}

\author{
Laifang $\mathrm{Li}^{1,5} \cdot$ Wenhong $\mathrm{Li}^{1} \cdot$ Tristan Ballard $^{2} \cdot \mathrm{Ge} \mathrm{Sun}^{3} \cdot$ Marc Jeuland $^{4}$
}

Received: 9 December 2014 / Accepted: 29 June 2015

(C) Springer-Verlag Berlin Heidelberg 2015

\begin{abstract}
Kiremt-season (June-September) precipitation provides a significant water supply for Ethiopia, particularly in the central and northern regions. The response of Kiremt-season precipitation to climate change is thus of great concern to water resource managers. However, the complex processes that control Kiremt-season precipitation challenge the capability of general circulation models (GCMs) to accurately simulate precipitation amount and variability. This in turn raises questions about their utility for predicting future changes. This study assesses the impact of climate change on Kiremt-season precipitation using state-of-the-art GCMs participating in the Coupled Model Intercomparison Project Phase 5. Compared to models with a coarse resolution, high-resolution models (horizontal resolution $<2^{\circ}$ ) can more accurately simulate precipitation, most likely due to their ability to capture precipitation induced by topography. Under the Representative Concentration Pathway (RCP) 4.5 scenario, these high-resolution models project an increase in precipitation
\end{abstract}

Wenhong Li

wenhong.li@duke.edu

1 Earth and Ocean Sciences, Nicholas School of the Environment, Duke University, 321C Old Chemistry Bldg, P.O. Box 90227, Durham, NC 27708, USA

2 Environmental Sciences, Trinity College of Arts and Sciences, Duke University, Durham, NC 27708, USA

3 Eastern Forest Environmental Threat Assessment Center, USDA Forest Service, Raleigh, NC 27606, USA

4 Sanford School of Public Policy and Duke Global Health Institute, Duke University, Durham, NC 27708, USA

5 Present Address: Physical Oceanography Department, Woods Hole Oceanographic Institution, Woods Hole, MA 02543, USA over central Highlands and northern Great Rift Valley in Ethiopia, but a decrease in precipitation over the southern part of the country. Such a dipole pattern is attributable to the intensification of the North Atlantic subtropical high (NASH) in a warmer climate, which influences Ethiopian Kiremt-season precipitation mainly by modulating atmospheric vertical motion. Diagnosis of the omega equation demonstrates that an intensified NASH increases (decreases) the advection of warm air and positive vorticity into the central Highlands and northern Great Rift Valley (southern part of the country), enhancing upward motion over the northern Rift Valley but decreasing elsewhere. Under the RCP 4.5 scenario, the high-resolution models project an intensification of the NASH by $15\left(3 \times 10^{5} \mathrm{~m}^{2}\right.$ $\mathrm{s}^{-2}$ ) geopotential meters (stream function) at the $850-\mathrm{hPa}$ level, contributing to the projected precipitation change over Ethiopia. The influence of the NASH on Kiremtseason precipitation becomes more evident in the future due to the offsetting effects of two other major circulation systems: the East African Low-level Jet (EALLJ) and the Tropical Easterly Jet (TEJ). The high-resolution models project a strengthening of the EALLJ, but a weakening of the TEJ. Future changes in the EALLJ and TEJ will drive this precipitation system in opposite directions, leading to small or no net changes in precipitation in Ethiopia.

Keywords Ethiopian Kiremt-season precipitation . CMIP5 model simulations · Climate change impact · North Atlantic subtropical high

\section{Introduction}

As in many countries in Africa, secure rural livelihoods and economic production in Ethiopia rely heavily on water 
availability (e.g. Tefera 2012; Evangelista et al. 2013; Megersa et al. 2014). Rainfall constitutes almost all of the water resources currently used in agriculture, which contributes to nearly $50 \%$ of national GDP and more than $80 \%$ of total employment (CIA 2014). Although Ethiopia is considered to be relatively water abundant, interannual and spatial variability of rainfall is high, rendering large parts of the country prone to drought and food insecurity. Meanwhile, rapid population growth and economic development is increasing the demand for food and water (World Bank 2008; Thornton et al. 2010). Thus, understanding and accurately predicting precipitation are especially important for enacting effective climate change adaptation policies and enhancing sustainability in this region.

Influenced by seasonally varying rainfall-generation systems, precipitation over Ethiopia shows clear seasonality (Gissila et al. 2004; Korecha and Barnston 2007). Climatologically, October to January is the dry season (the Bega season) while March to May constitutes a short rainy season (the Belg season). The major rainy season, or Kiremt season, occurs between June and September, contributes $50-80 \%$ of annual precipitation, and is the major source of water used in rainfed agriculture. Thus, future variation in Kiremt-season precipitation would have important implications for food security and rural livelihoods in Ethiopia.

The intensity of Kiremt-season precipitation is a result of the combined effects of seasonal movement of the InterTropical Convergence Zone (ITCZ), local land surface heating, and topographic forcing exerted by the Ethiopian Highlands via orographic lift (Segele and Lamb 2005; Slingo et al. 2005). In boreal summer seasons, the ITCZ migrates northward and persists over Ethiopia, bringing moisture into the region at the lower troposphere that sustains precipitation. At the same time, summer heating of the land surface enhances local conditional instability and increases the likelihood of precipitation. This is further fueled by the orographic lift of air masses passing over the Ethiopian Highlands (Slingo et al. 2005). The interactions among seasonal ITCZ movement, land surface heating, and topographic lifting provide favorable, but complex, conditions for the generation and development of precipitation.

The processes responsible for Kiremt-season precipitation are modulated by multiple large-scale circulation systems, including the upper tropospheric Tropical Easterly Jet (TEJ), the East African Low-Level Jet (EALLJ), and the Azores High/North Atlantic Subtropical High (NASH) (Diro et al. 2011b). The intensity and position of the TEJ influences Ethiopian precipitation mainly through modulating vertical motion and synoptic-scale disturbances that provide instability conditions for rainfall generation (Hulme and Tosdevin 1989). A strong and northward positioning of the TEJ usually results in excessive precipitation over Ethiopia (Segele and Lamb 2005). In addition, the
EALLJ, a fast-flowing low-level southerly wind along Eastern Africa, modulates precipitation by impacting moisture transport from the tropical Indian Ocean. With an intensified EALLJ, much of Ethiopia tends to receive more moisture and thus excessive precipitation (Viste and Sorteberg 2013). Finally, NASH variation has been found to have a strong correlation with the Kiremt-season precipitation (Segele et al. 2009a) although detailed processes remain inconclusive.

The three large-scale systems, in turn, are modulated by various climate modes, making Kiremt-season precipitation particularly sensitive to climate variability and potentially sensitive to climate change (Rodríguez-Fonseca 2015; Segele et al. 2015). For example, the El Niño Southern Oscillation (ENSO) significantly alters the position and intensity of the TEJ, leading to decreased (increased) Kiremt-season precipitation during strong El Niño (La Niña) years (Nicholson and Kim 1997; Segele and Lamb 2005). Likewise, the Indian Ocean Dipole (IOD) and Mediterranean Ocean sea surface temperatures affect EALLJ dynamics and moisture supply, respectively (Rowell 2003; Ummenhofer et al. 2009). In addition, sea surface temperature anomalies (SSTAs) over the North Atlantic can influence the temporal and spatial variability of the NASH (Kushnir et al. 2010) and mainly influence the low frequency variability of precipitation (Shanahan et al. 2009).

Such a complex mixture of processes governing Ethiopian Kiremt-season precipitation pose significant challenges for general circulation models (GCMs) (Joly et al. 2007; Otieno and Anyah 2013). To date, it remains unclear (1) what specific processes contribute to the performance of GCMs in accurately simulating past variations in Kiremtseason precipitation; and (2) how Kiremt-season precipitation will change over Ethiopia when $\mathrm{CO}_{2}$ and other greenhouse gas concentrations in the atmosphere increase in the future.

This study aims to explore the factors contributing to GCM skill in simulating Kiremt-season precipitation and its future changes. The specific scientific questions targeted in this study are: (i) How well can state-of-the-art GCMs simulate Ethiopian Kiremt-season precipitation?; (ii) Will the precipitation regime change as the climate warms?; and (iii) What processes/factors cause the projected changes in precipitation? By addressing these questions, this study hopes to contribute to improvements of GCM simulations of Ethiopian precipitation. This in turn will support efforts to predict and mitigate climate change impacts on water resources in the region.

The remainder of the manuscript is organized as follows. Section 2 presents the observational datasets used to assess the CMIP5 models' simulations and describes the analytical methods used in this study. The performance of GCMs in simulating Historical Ethiopian precipitation and the 
analysis of future precipitation projections are described in Sect. 3. The possible factors/processes responsible for these future precipitation changes are discussed in Sect. 4 . Finally, Sect. 5 provides conclusions.

\section{Data and methods}

\subsection{Observations}

In this study, we used three separate observational datasets to construct a comprehensive monthly precipitation database over Ethiopia. These include the National Oceanic and Atmospheric Administration (NOAA)'s PRECipitation REConstruction over Land (Prec/L) dataset (Chen et al. 2002), the Global Precipitation Climatology Centre (GPCC) dataset (Rudolf et al. 2010), and the Climate Research Unit (CRU) of the University of East Anglia dataset (Harris et al. 2014). To minimize the uncertainty introduced by the choice of observational datasets, an average of these three datasets was used to represent our best estimate of the true observed precipitation. In this study, the Kiremt-season precipitation was calculated as the average from June to September (JJAS).

Variables used to represent the key atmospheric processes influencing Kiremt-season precipitation include 850-hPa wind and geopotential height, $500 \mathrm{hPa}$ vertical velocity (omega), and $200 \mathrm{hPa}$ zonal wind. Historical estimations of these variables are available from the National Centers for Environmental Prediction (NCEP)/National Center for Climate Research (NCAR) reanalysis dataset (Kalnay et al. 1996). The NCEP/NCAR dataset was used due to its longer temporal coverage relative to those in other reanalysis products.

The omega equation (Holton 2004) was analyzed to diagnose the large-scale circulation processes responsible for the variation of precipitation over Ethiopia:

$\left(\nabla_{h}^{2}+\frac{f}{N^{2}} \frac{\partial^{2}}{\partial z^{2}}\right) \omega=\frac{g}{\bar{\theta}^{2} N^{2}} \nabla_{h}^{2}\left(-V_{g} \cdot \nabla_{h} \theta\right)-\frac{f}{N^{2}}\left(-V_{g} \cdot \nabla_{h} \zeta\right)$

where, $\omega=\frac{d p}{d t}$ is vertical motion at a pressure coordinate, $\theta$ is potential temperature, $N^{2}=\frac{g}{\theta} \frac{d \bar{\theta}}{d z}$ is buoyancy frequency, and $\zeta=\frac{\partial v_{g}}{\partial x}-\frac{\partial u_{g}}{\partial y}$ is geostrophic relative vorticity.

\subsection{GCM simulations}

Simulations of Ethiopian Kiremt-season precipitation were analyzed using the output from 30 state-of-the-art GCMs (Table 1) participating in Phase-5 of the Coupled Model Intercomparison Project (CMIP5). Two experiments were considered in this study: the Historical (1950-1999) and the Representative Concentration Pathway (RCP) 4.5 scenario (2050-2099). These two experiments are the core of the CMIP5 long-term experiments, which are given high priority by all modeling centers (Taylor et al. 2009, 2012). The Historical experiments represent the current climate and are driven by observed changes in atmospheric composition. The RCP4.5 is a midrange mitigation emission scenario, within which the $\mathrm{CO}_{2}$ concentration increases to $650 \mathrm{ppm}$ in 2100 and is stabilized afterward. Meanwhile, the radiative forcing steadily increases to $4.5 \mathrm{~W} \mathrm{~m}^{-2}$ in 2100 and then similarly stabilizes (Moss et al. 2010; Taylor et al. 2012). Kiremt-season precipitation under the RCP4.5 scenario was then compared with that under the Historical run to assess future changes. Here we analyze one run per model, thereby giving equal weight to each model.

Simulations of atmospheric circulation systems known to influence Ethiopian Kiremt-season precipitation, including the TEJ, EALLJ, and NASH, as well as SSTs were analyzed to obtain a process-level understanding of the projected changes in precipitation.

\section{Results}

\subsection{CMIP5 model simulations of Ethiopian Kiremt-season Historical precipitation}

In order to evaluate the performance of GCMs over Ethiopia, we compared the 50-year climatology of area-averaged Kiremt-season precipitation (1950-1999) from 30 CMIP5 GCMs with observations (Fig. 1). Compared to observations $\left(3.8 \mathrm{~mm} \mathrm{day}^{-1}\right)$, the CMIP5 models generally underestimate precipitation with the multi-model mean precipitation being $3 \mathrm{~mm}$ day $^{-1}$. This dry bias is not caused by specific outlier models. Among the 30 GCMs, 23 (77 \%) models simulate lower precipitation than the observations, and for 14 out of the $30(47 \%)$ models, the dry bias exceeds one standard deviation of the observed precipitation (Fig. 1). Meanwhile, only $6(20 \%)$ models overestimate precipitation, and one model captures the rainfall climatology and variability during the 2 nd half of the twentieth century.

The underestimation of GCM-simulated Kiremt-season precipitation might be due to insufficient model resolution. Previous studies suggest that topography over the Ethiopian Highlands provides mechanical uplifting and thermal forcing to air parcels along the southwesterly flows, which is a primary driver of Kiremt-season precipitation (Segele and Lamb 2005). These important topographical features cover an $8^{\circ} \times 8^{\circ}$ area and require at least 16 model grids to resolve them (Pielke 2002). Thus, theoretically, horizontal resolution of $<2^{\circ}$ is needed for the GCMs to simulate the impact of the topography on Ethiopian precipitation (Pielke 2002; 
Table 1 Description of CMIP5 models used in this study

\begin{tabular}{|c|c|c|}
\hline Modeling group & CMIP5 model id & $\begin{array}{l}\text { AGCM resolution } \\
\text { (nLat. } \times \text { nLon.) }\end{array}$ \\
\hline $\begin{array}{l}\text { Atmosphere and Ocean Research Institute (The University of } \\
\text { Tokyo), National Institute for Environmental Studies, and Japan } \\
\text { Agency for Marine-Earth Science and Technology, Japan }\end{array}$ & MIROC-ESM & $\mathrm{T} 42$ \\
\hline $\begin{array}{l}\text { Beijing Climate Center, China Meteorological Administration, } \\
\text { China }\end{array}$ & $\begin{array}{l}\text { BCC-CSM1-1 } \\
\text { BCC-CSM1-1-M }\end{array}$ & $\begin{array}{l}\text { T42 } \\
\text { T106 }\end{array}$ \\
\hline Beijing Normal University, China & BNU-ESM & $\mathrm{T} 42$ \\
\hline Canadian Centre for Climate Modelling and Analysis, Canada & CanESM2 & T63 \\
\hline $\begin{array}{l}\text { Centre National de Recherches Meteorologiques/Centre Europeen } \\
\text { de Recherche et Formation Avancees en Calcul Scientifique, } \\
\text { France }\end{array}$ & CNRM-CM5 & T127 \\
\hline Centro Euro-Mediterraneo per I Cambiamenti Climatici, Italy & $\begin{array}{l}\text { CMCC-CM } \\
\text { CMCC-CMS }\end{array}$ & $\begin{array}{l}240 \times 480 \\
96 \times 192\end{array}$ \\
\hline $\begin{array}{l}\text { Commonwealth Scientific and Industrial Research Organization/ } \\
\text { Bureau of Meteorology, Australia }\end{array}$ & $\begin{array}{l}\text { ACCESS 1.0 } \\
\text { ACCESS } 1.3\end{array}$ & $\begin{array}{l}144 \times 192 \\
144 \times 192\end{array}$ \\
\hline $\begin{array}{l}\text { Commonwealth Scientific and Industrial Research Organization/ } \\
\text { Queensland Climate Change Centre of Excellence, Australia }\end{array}$ & CSIRO-Mk3.6.0 & T63 \\
\hline Community Earth System Model Contributor, USA & $\begin{array}{l}\text { CESM1-BGC } \\
\text { CESM1-CAM5 }\end{array}$ & $\begin{array}{l}192 \times 228 \\
96 \times 144\end{array}$ \\
\hline Institute for Numerical Mathematics, Russia & INM-CM4 & $120 \times 180$ \\
\hline Institut Pierre-Simon Laplace, France & $\begin{array}{l}\text { IPSL-CM5A-LR } \\
\text { IPSL-CM5A-MR }\end{array}$ & $\begin{array}{l}95 \times 96 \\
143 \times 144\end{array}$ \\
\hline $\begin{array}{l}\text { LASG, Institute of Atmospheric Physics, Chinese Academy of } \\
\text { Sciences, China }\end{array}$ & FGOALS-s2 & $108 \times 128$ \\
\hline $\begin{array}{l}\text { LASG, Institute of Atmospheric Physics, Chinese Academy of } \\
\text { Sciences and CESS, Tsinghua University, China }\end{array}$ & FGOALS-g2 & $60 \times 128$ \\
\hline Max Planck Institute for Meteorology, Germany & $\begin{array}{l}\text { MPI-ESM-LR } \\
\text { MPI-ESM-MR }\end{array}$ & $\begin{array}{l}\text { T63 } \\
\text { T63 }\end{array}$ \\
\hline Meteorological Research Institute, Japan & MRI-CGCM3 & T159 \\
\hline Met Office Hadley Centre, United Kingdom & $\begin{array}{l}\text { HadGEM2-CC } \\
\text { HadGEM2-ES }\end{array}$ & $\begin{array}{l}144 \times 192 \\
144 \times 192\end{array}$ \\
\hline NOAA, Geophysical Fluid Dynamics Laboratory, USA & $\begin{array}{l}\text { GFDL-CM3 } \\
\text { GFDL-ESM2G } \\
\text { GFDL-ESM2 M }\end{array}$ & $\begin{array}{l}90 \times 144 \\
90 \times 144 \\
90 \times 144\end{array}$ \\
\hline National Center for Atmospheric Research, USA & CCSM4 & $180 \times 288$ \\
\hline NASA Goddard Institute for Space Studies, USA & $\begin{array}{l}\text { GISS-E2-H } \\
\text { GISS-E2-R }\end{array}$ & $\begin{array}{l}90 \times 144 \\
90 \times 144\end{array}$ \\
\hline Norwegian Climate Centre, Norway & NorESM1-M & $96 \times 144$ \\
\hline
\end{tabular}

The 14 high-resolution models are marked in bold
Feser et al. 2011). Using $2^{\circ}$ horizontal-resolution as a cut-off, we separated the 30 CMIP5 models into two groups: high-resolution models (14) and low-resolution models (16).

Comparing the two groups, the high-resolution models generally outperform the low-resolution models in simulating the area-averaged precipitation (Fig. 1). Specifically, the ensemble of high-resolution models shows an average precipitation rate over Ethiopia of $3.69 \mathrm{~mm} \mathrm{day}^{-1}$, which is very similar to observations (Fig. 1). In contrast, the precipitation rate in the ensemble of low-resolution models is
$<2.6 \mathrm{~mm} \mathrm{day}^{-1}$, which is a roughly $30 \%$ underestimate of observed precipitation.

The better performance of the high-resolution models is also manifest in the spatial distribution of simulated precipitation over Ethiopia. Observations indicate that Kiremt-season precipitation is greatest over the Great Rift Valley (around $10^{\circ} \mathrm{N}, 37^{\circ} \mathrm{E}$; Fig. $2 \mathrm{c}$ ), where precipitation exceeds $8 \mathrm{~mm} \mathrm{day}^{-1}$ on average. The high-resolution models simulate an average precipitation rate of slightly more than $8 \mathrm{~mm}$ day $^{-1}$ over the Great Rift Valley, consistent with observations (Fig. 2c, f). In contrast, the low-resolution 


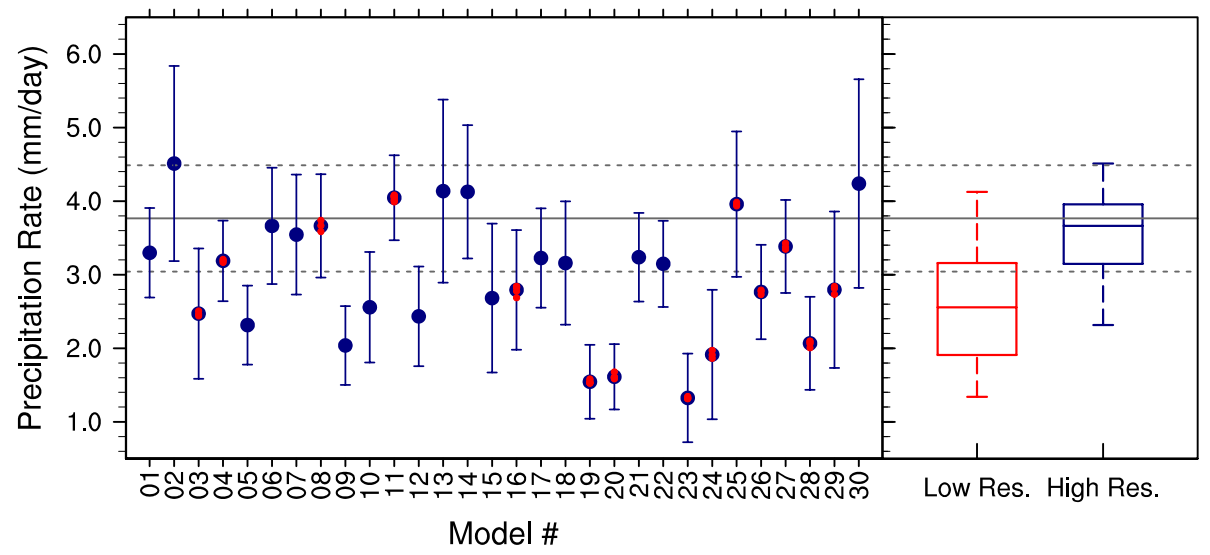

Fig. 1 Kiremt-season precipitation (1950-1999; unit: $\mathrm{mm} \mathrm{day}^{-1}$ ) simulated by 30 CMIP5 GCMs. The dots are the 50-year climatology of precipitation simulated by each model. The error bars represent $95 \%$ confidence interval of simulated precipitation. The small red dots are the precipitation climatology simulated by each ensemble members. The solid and dashed gray horizontal lines are the observed Kiremt-season precipitation climatology (1950-1999) and

models underestimate the precipitation by $2 \mathrm{~mm} \mathrm{day}^{-1}$ (Fig. 2i), indicating that they cannot adequately simulate the rainfall generation processes of this region, probably due to issues related to topography.

This topographic influence on model performance is especially evident when comparing the simulations of Kiremt-season precipitation to those of the long dry (Bega) season and the short rainy (Belg) season. Specifically, in the Bega and Belg seasons, the simulated spatial pattern and amount of precipitation are similar in both high-resolution and low-resolution models (Fig. 2d-g). However, the high-resolution models generally outperform the low-resolution models in capturing the patterns and amount of precipitation in Ethiopia (Fig. 2). The comparison of simulated precipitation between the high- and low-resolution CMIP5 models suggests that the ability to resolve topographic forcing mechanism likely lead to a better simulation of Ethiopian precipitation by GCMs (Bell et al. 2004). This result is consistent with Slingo et al. (2005), who perform Atmospheric Model Intercomparison Project (AMIP)-type simulations and notice an enhancement of East African precipitation in models that better capture topographical features.

In summary, the evaluation of CMIP5 modeling results suggests that horizontal resolution contributes to the skill of GCMs in simulating important features of Ethiopian Kiremt-season precipitation. Specifically, low-resolution models with a horizontal resolution coarser than $2^{\circ}$ generally underestimate precipitation over the Great Rift Valley region where topographic forcing is a primary driver of precipitation. In contrast, high-resolution models more accurately reproduce Historical precipitation rates and patterns presumably because they can better resolve the
$95 \%$ confidence interval, respectively. The whisker plots summarize the climatology of Kiremt-season precipitation simulated by lowresolution (red box) and high-resolution models (blue box). The middle lines represent the median of precipitation as simulated by two group models. The top and bottom of the box represent the 75- and 25-percentile precipitation, respectively. The top and bottom lines of the whisker plots show the maximum and minimum precipitation

topographic forcing and precipitation processes. This suggests that increasing horizontal resolution will generally help to improve GCM simulations of Ethiopian Kiremtseason precipitation.

\subsection{Projections of future precipitation change over Ethiopia}

Future changes in Kiremt-season precipitation are shown in Fig. 3, according to the simulation under the RCP 4.5 scenario (2050-2099). Since high-resolution models generally outperform low-resolution models in simulating Historical precipitation (Figs. 1, 2), the projections by the 14 high-resolution CMIP5 models are given high weight $(\mathrm{Li}$ et al. 2008). Figure 3 a shows the changes in area-averaged Kiremt-season precipitation projected by the high-resolution models. Overall, the ensemble of high-resolution models predicts no significant change in precipitation $\left(-0.07 \mathrm{~mm} \mathrm{day}^{-1}\right)$ over Ethiopia by the second half of the twenty-first century (2050-2099). Furthermore, a majority of the models show only a slight deviation (not statistically significant by $t$ test) from their individual Historical runs (Fig. 3a). In contrast, the low-resolution models project an increase in Kiremt-season precipitation (Fig. 3b). However, due to the lower skill in simulating the Historical precipitation, their projection of future climate change is less credible than that by the high-resolution models. In the following sections, we focus on the high-resolution models.

The weak changes in area-averaged precipitation might be due to the spatially heterogeneous response of precipitation to GHG forcing as shown in Fig. 4. The ensemble of the high-resolution models projects an increase in 
(a) Obs. Bega Season

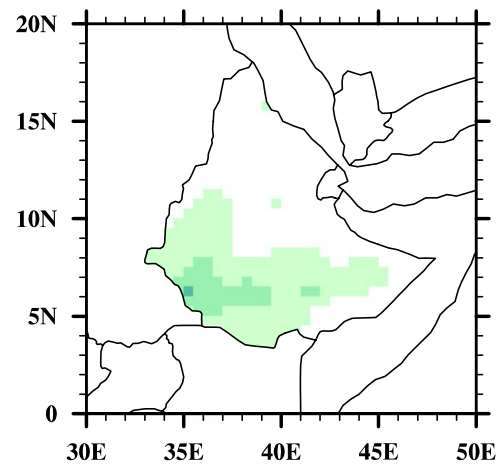

(d) Bega Season (HiRes)

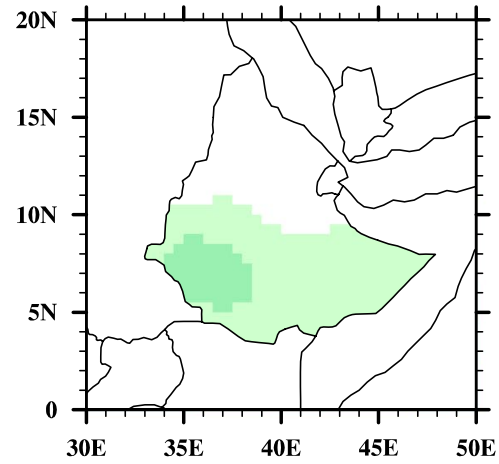

(g) Bega Season (LowRes) (b) Obs. Belg Season

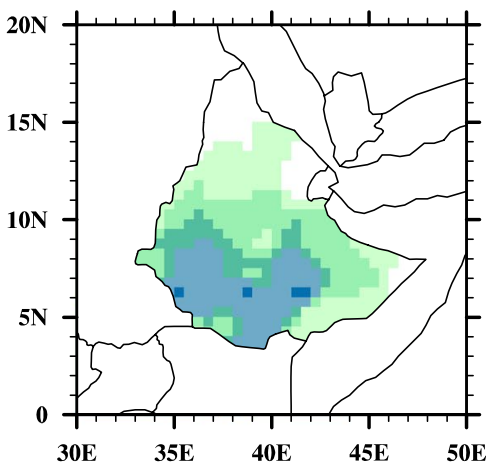

(e) Belg Season (HiRes)

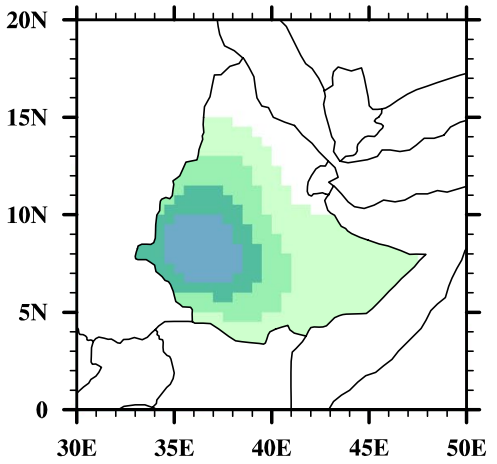

(h) Belg Season (LowRes) (c) Obs. Kiremt Season

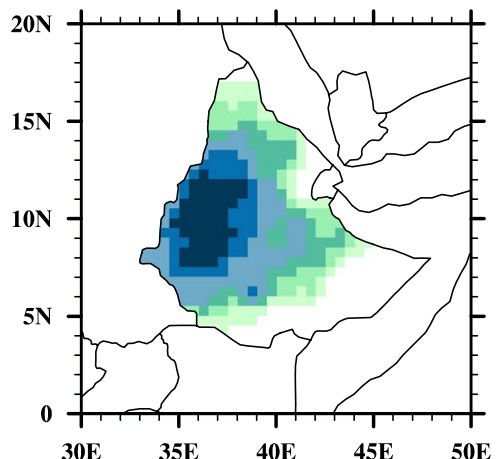

(f) Kiremt Season (HiRes)

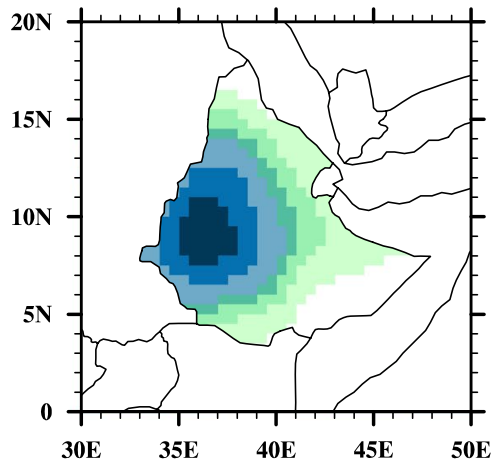

(i) Kiremt Season (LowRes)

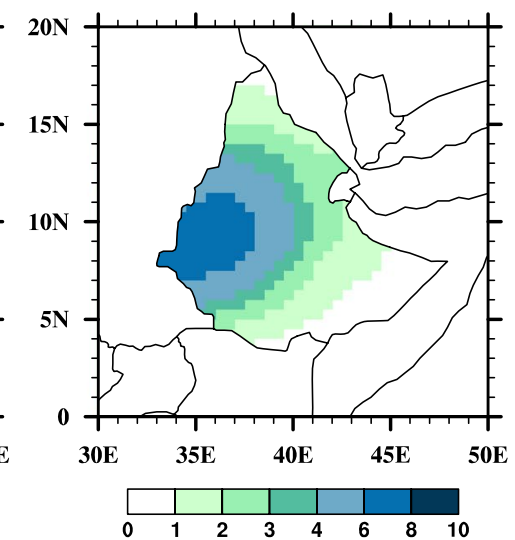

Fig. 2 Climatology (1950-1999) of Ethiopian precipitation (shaded, unit: $\mathrm{mm} \mathrm{day}^{-1}$ ) during the long dry Bega (left panels), the short rainy Belg (middle panels) and the long rainy Kiremt (right panels)

Kiremt-season precipitation over the central Highlands and northern Great Rift Valley in Ethiopia and a decrease elsewhere, presenting a north-south oriented dipole pattern (Fig. 4).

Such a dipole pattern is projected by more than $71 \%$ of the high-resolution models (Fig. 4). 10 out of the 14 models consistently show the dipole pattern present in the ensemble, although the magnitude of the seasons in observations $(\mathbf{a}-\mathbf{c})$, and simulations by high-resolution CMIP5 models (d-f) and low-resolution models $(\mathbf{g}-\mathbf{i})$ in the Historical run

precipitation response differs among these models. Meanwhile, three models project a uniform increase in precipitation over Ethiopia, and one model projects a uniform decrease in precipitation. Overall, the dipole pattern in precipitation change appears to represent the most likely response of Ethiopian Kiremt-season precipitation to GHG forcing, according to the simulations by high-resolution models. 


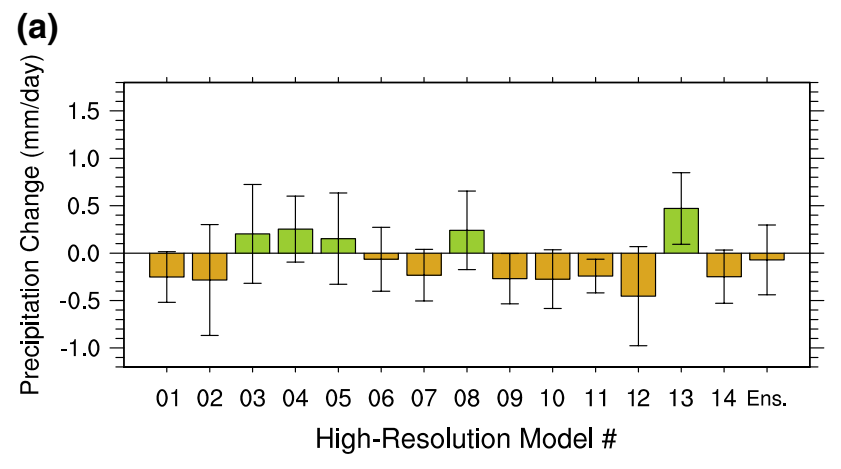

(b)

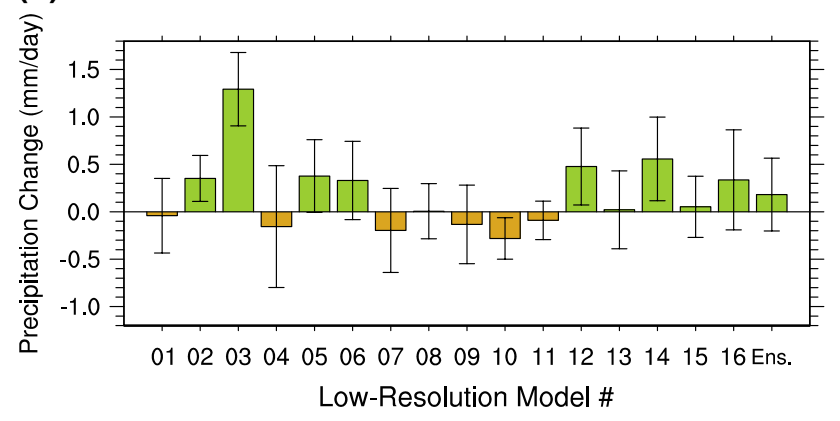

Fig. 3 Changes in Kiremt-season precipitation (bar, unit: $\mathrm{mm} \mathrm{day}^{-1}$ ) from the Historical run (1950-1999) to the RCP 4.5 scenario (20502099) as projected by a 14 high-resolution models, and b 16 lowresolution models, as well as the ensemble of each group of models. The green bars denote models that project increases in precipitation, while the brown bars are the models that project decreases in precipitation. The error bars are the $95 \%$ confidence interval of the projected changes in precipitation

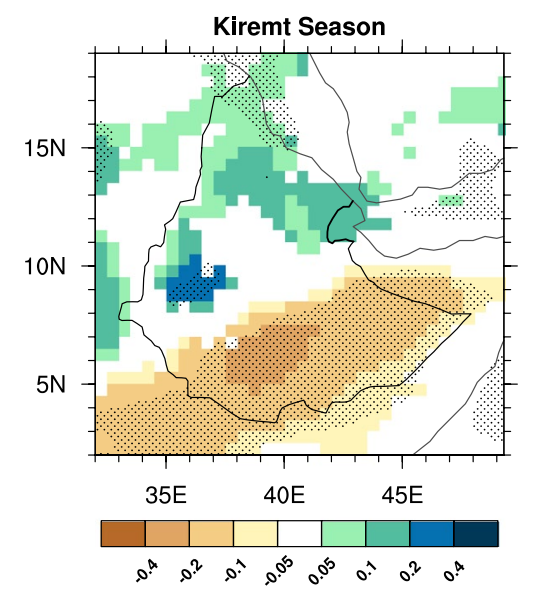

Fig. 4 Changes in Kiremt-season precipitation (shaded, unit: $\mathrm{mm}$ day $^{-1}$ ) as projected by the high-resolution CMIP5 models. The precipitation changes are calculated as the difference between the simulations under the RCP 4.5 scenario (2050-2099) and the Historical run (1950-1999). Only the grid cells with more than $70 \%$ of the high-resolution models agree on the sign of precipitation change are shown. The stippled are the grid cells where precipitation change is significant at $90 \%$ confidence level

\section{Causes of Ethiopian Kiremt-season precipitation change}

The high-resolution models project a dipole pattern of future Kiremt-season precipitation changes under the RCP4.5 scenario (Fig. 4). This spatially non-uniform distribution of precipitation change has important implications for water resource management in Ethiopia. A shift in the spatial distribution of precipitation by the second half of the twenty-first century will contribute to existing water resources challenges, such as flooding and drought, adding an important new complication to current changes in population and social dynamics. Understanding the causes of future precipitation change will provide a more solid scientific basis for developing policies and strategies for responding to such changes.

\subsection{Factors contributing to Kiremt-season precipitation}

Ethiopian Kiremt-season precipitation is influenced by multiple circulation systems, especially the EALLJ, TEJ, and NASH. These systems directly influence precipitation over Ethiopia (Nicholson and Grist 2003; Segele and Lamb 2005), and the impact of SSTA modes on Ethiopian precipitation is primarily driven by modifications to the abovementioned systems (e.g. Rowell 2003; Segele and Lamb 2005; Shanahan et al. 2009; Ummenhofer et al. 2009; Diro et al. 2011a).

Figure 5 summarizes the observed and modeled relationships among the three large-scale circulation systems and Ethiopian precipitation in the Kiremt season. Here, a composite method based on EALLJ, TEJ, and NASH circulations was used to highlight the relationships. The cases for this composite analysis were selected when the anomalies of circulation indices exceeded one standard deviation. ${ }^{1}$ The high-resolution CMIP5 models qualitatively capture the observed relationship between large-scale circulation index and Ethiopian precipitation (Fig. 5).

By comparing the different patterns of precipitation anomalies to variations of the EALLJ (Fig. 5a, d), TEJ (Fig. 5b, e) and NASH intensity (Fig. 5c, f), we found that the projected dipole pattern in precipitation change (Fig. 4) does not appear related to the EALLJ or TEJ but rather resembles the precipitation pattern associated with the NASH (Fig. 5). Specifically, both the EALLJ and TEJ changes tend to cause domain-wide changes

\footnotetext{
1 The TEJ index is defined as the intensity of $200 \mathrm{hPa}$ easterly wind with in the $30^{\circ} \mathrm{E}-70^{\circ} \mathrm{E}$ and $7^{\circ} \mathrm{N}-20^{\circ} \mathrm{N}$ domain. The EALLJ is defined as the intensity of $850 \mathrm{hPa}$ southerly wind averaged over the domain of $35^{\circ} \mathrm{E}-55^{\circ} \mathrm{E}, 5^{\circ} \mathrm{S}-10^{\circ} \mathrm{N}$. The NASH intensity is defined as the maximum of $850 \mathrm{hPa}$ geopotential height over the subtropical North Atlantic basin.
} 
(a) EALLJ Composite

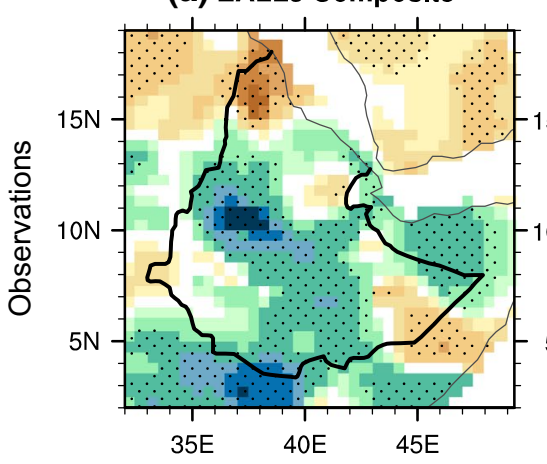

(d) EALLJ Composite

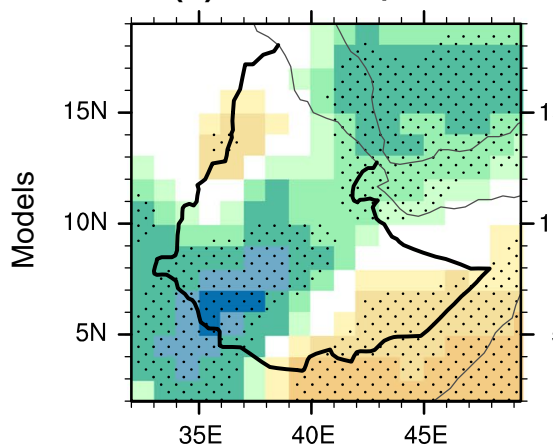

(b) TEJ Composite

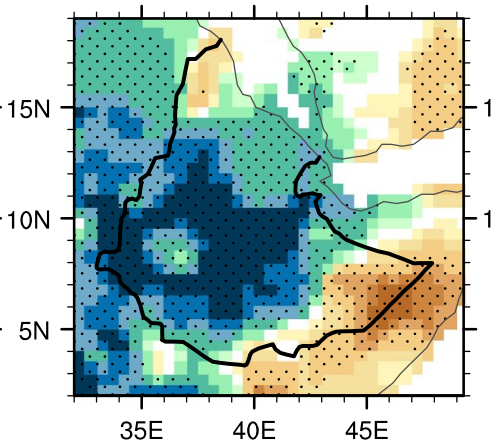

(e) TEJ Composite (c) NASH Composite

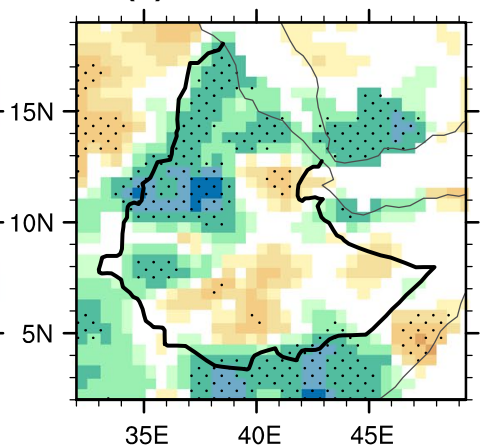

(f) NASH Composite
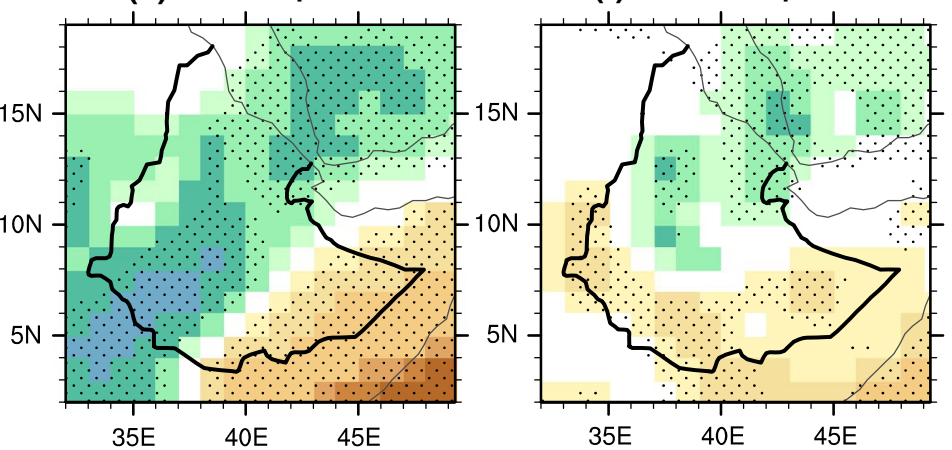

$\begin{array}{llllllllllllllll}-1.2 & -1 & -0.8 & -0.6 & -0.4 & -0.2 & -0.1 & 0.1 & 0.2 & 0.4 & 0.6 & 0.8 & 1 & 1.2\end{array}$

Fig. 5 Differences of Ethiopian Kiremt-season precipitation (shaded; unit: $\mathrm{mm} \mathrm{day}^{-1}$ ) between strong and weak $\mathbf{a}$ and $\mathbf{d}$ EALLJ; b and $\mathbf{e}$ TEJ, and $\mathbf{c}$ and $\mathbf{f} \mathrm{NASH}$. The upper (lower) panels are the observed (high-resolution model simulated) relationship between circulation and precipitation. The strong (weak) cases are defined as when these circulation indices are above one standard deviation (below negative one standard deviation). The stippled grid cells are where the differences in precipitation are significant at $90 \%$ confidence level according to student $t$-test in precipitation over Ethiopia. A stronger EALLJ contributes to above-normal Kiremt-season precipitation (Fig. 5a, d) by increasing moisture transport from the tropical oceans (Segele et al. 2009b). Meanwhile, the intensification of the TEJ can enhance the upward motion southward of the jet core (Segele and Lamb 2005; Korecha and Barnston 2007). As a result, excessive precipitation occurs over Ethiopia (Fig. 5b, e). In contrast, the intensification of the NASH circulation increases precipitation in the northern part of the country while decreasing precipitation in the south (Fig. 5c, f). Such a precipitation pattern resembles the projected precipitation change (Fig. 4), indicating the potential importance of the NASH circulation in driving future precipitation patterns over Ethiopia.

Analysis of the observed Historical atmospheric circulations suggests that the NASH might contribute to Kiremt-season precipitation by altering moisture flow and atmospheric vertical motion. An intensification of the NASH usually accompanies a wave-train pattern, with an anomalous anticyclone over the North Atlantic, a cyclone off the coast of West Africa, and an anticyclone over the African continent (Fig. 6a). The anticyclone over the African continent weakens the prevailing southwesterly flow during the Kiremt season and thus supplies less moisture to the southern portion of the country (Fig. 6a). To the north, the northerly flow along the anticyclone brings moisture from the Red Sea, one of the moisture source regions contributing to Ethiopian Kiremt-season precipitation (Viste and Sorteberg 2013). Therefore, precipitation in the north is intensified with a stronger NASH (Fig. 6a).

The influence of the NASH is also manifested in the $500 \mathrm{hPa}$ vertical motion. In Ethiopia, upward motion is intensified to the north and weakened to the south (Fig. 6b), favoring the observed dipole pattern in precipitation. According to the omega equation [Eq. (1)], the increase (decrease) in upward motion to the north (south) might result from a combination of temperature and vorticity advection associated with the circulation change. 


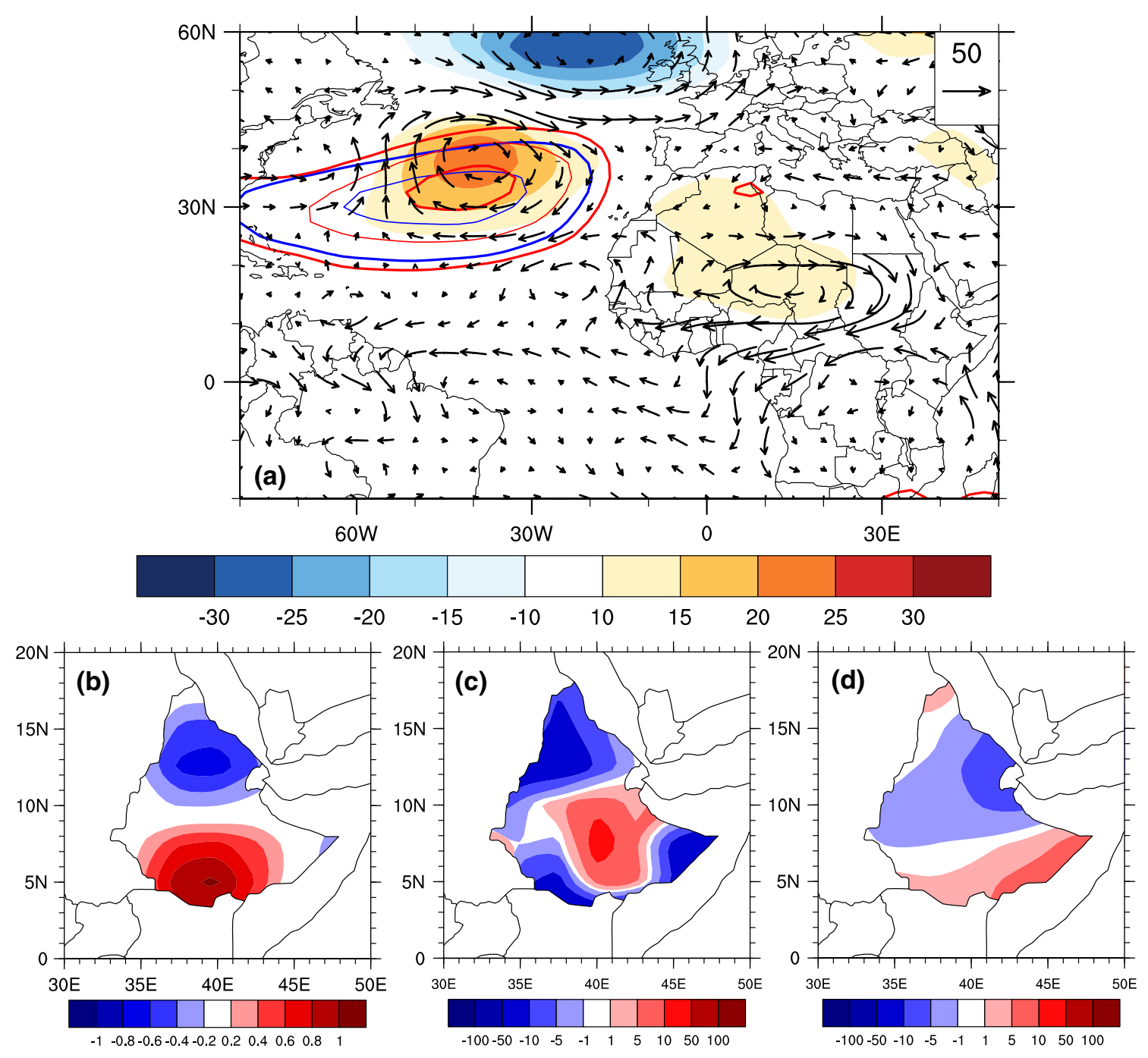

Fig. 6 a Differences of atmospheric moisture flux (vector, unit: $\mathrm{kg}$ $\mathrm{m}^{-1} \mathrm{~s}^{-1}$ ) between strong and weak NASH years and $850 \mathrm{hPa}$ geopotential height (shaded, unit: geopotential meters); the contours (contour interval is 20 geopotential meters) are the $850 \mathrm{hPa}$ geopotential height composite upon strong (red contours) and weak (blue contours) NASH years. The bold contours are 1560- and 1600-geopoten-

Mechanistically, the anomalous circulation associated with a strong NASH brings more positive vorticity from the high latitude to the northern domain, enhancing upward motion in order to balance the vorticity input (Fig. 6c). At the same time, a strong NASH increases advection of warm air in the northern part of Ethiopia and cold advections in the southern portion (Fig. 6d). As a result, air columns stretch (contract) in the north (south), leading to intensified (weakened) upward motion in the north (south). Collectively, the NASH induces changes in atmospheric circulation that tend to enhance (weaken) upward motion in the northern (southern) Ethiopia, leading to the dipole pattern of precipitation change. tial meter isolines; $\mathbf{b}$ differences of $500 \mathrm{hPa}$ vertical velocity $\left(\omega=\frac{d p}{d t}\right.$ unit: $\mathrm{Pa} \mathrm{s}^{-1}$ ) between strong and weak NASH years; and omega equation diagnostics of $500 \mathrm{hPa}$ vertical motion: c contribution of vorticity advection $\left(-\frac{\partial}{\partial z}\left[\vec{V}_{g} \cdot \nabla\left(f+\zeta_{g}\right)\right]\right.$ ); and $\mathbf{d}$ temperature advection $\left(\vec{V}_{g} \cdot \nabla T\right)$. In $\mathbf{c}$ and $\mathbf{d}$ blue denotes upward motion while red denotes downward motion

\subsection{Future changes to the NASH}

Consistent with observations, the projected dipole pattern in precipitation change is attributable to the intensification of the NASH in a warming climate. According to the ensemble of high-resolution models, $850 \mathrm{hPa}$ geopotential height in the NASH center will increase by 15 geopotential meters (Fig. 7a), ${ }^{2}$ suggesting a significant intensification of the high

\footnotetext{
${ }^{2}$ We also quantified the NASH intensity change using streamfunction. The results show that the streamfunction will increase by $3 \times 10^{5} \mathrm{~m}^{2} \mathrm{~s}^{-2}$ under RCP 4.5 scenario compared to Historical run, indicating an intensification of the NASH in a warmer climate.
} 

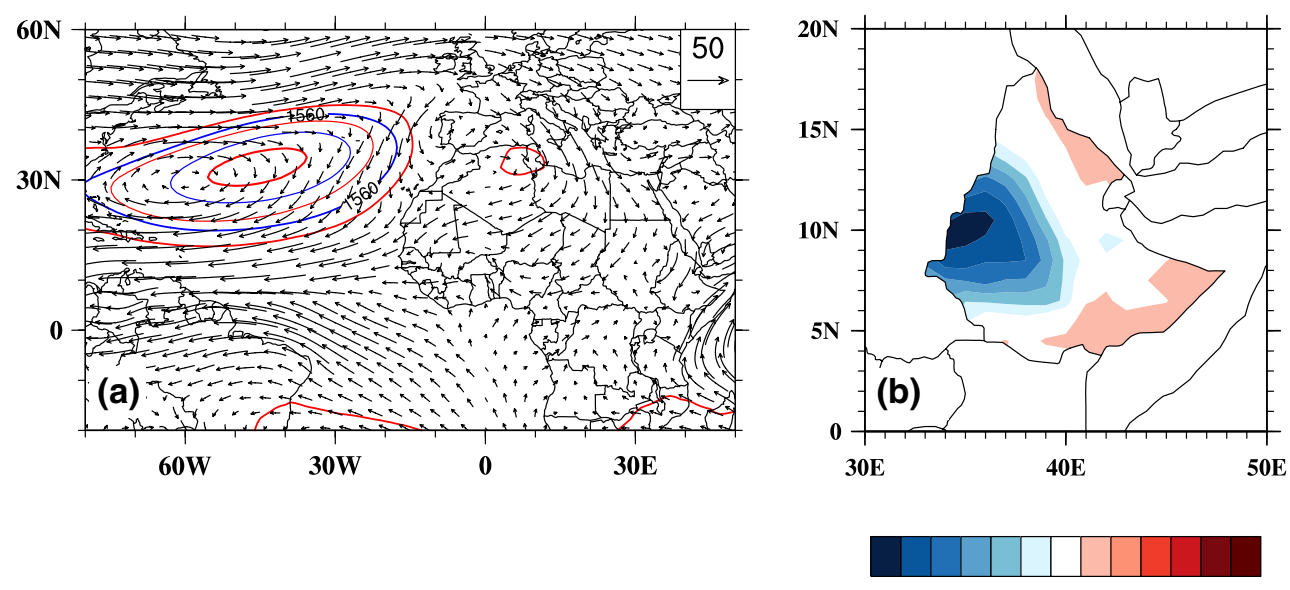

$2,0,8 \times 2,2 \times 68,2$

Fig. 7 a JJAS $850 \mathrm{hPa}$ geopotential height (contours; unit: geopotential meter) in the North Atlantic in the Historical run (19501999, blue), the RCP 4.5 scenarios (2050-2099, red), and changes of atmospheric moisture flux (vector, unit: $\mathrm{kg} \mathrm{m}^{-1} \mathrm{~s}^{-1}$ ) between RCP 4.5 and Historical run; and $\mathbf{b}$ changes in $500 \mathrm{hPa}$ omega field

pressure system under the RCP 4.5 scenario. The results are consistent with previous studies on the NASH circulation response to climate change ( $\mathrm{Li}$ et al. 2011, 2012, 2013).

Accompanying the intensification of the NASH, upward motion is enhanced over the northern Rift Valley but decreased in the southern portion of Ethiopia (Fig. 7b). Such changes in vertical motion are consistent with the simulated dipole pattern in precipitation changes. Overall, the projected changes in large-scale circulation and precipitation resemble the observed processes by which the NASH influences Ethiopian precipitation (Fig. 6). Thus, the intensified NASH most likely explains the projected changes in Ethiopian Kiremt-season precipitation.

The intensification of the NASH and the changes in precipitation, however, might not directly result from the projected SST changes. The ensemble of the high-resolution models projects an increase in SST worldwide (Fig. 8a), with an accelerated warming in the tropical Eastern Pacific and along the Gulf Stream extension over the subtropical North Atlantic (Fig. 8b). The warming over the tropical Eastern Pacific tends to reduce Ethiopian precipitation (Segele et al. 2009a; Diro et al. 2011a). Thus the SSTA pattern in the eastern tropical Pacific is unlikely to explain the projected precipitation changes (Fig. 4). In addition, the warming of SSTA along the Gulf Stream extension is more likely induced by an intensification of the NASH, rather than causing the intensification of the NASH. On the one hand, the strong NASH accelerate the SST warming along the Gulf stream extension through the wind-driven circulation and associated dynamics to SST (Wu et al. 2012). On the other, the warming of the SSTA over the North Atlantic tends to induce a low-pressure in the ocean surface which

(shaded, unit: $\mathrm{hPa} \mathrm{h}^{-1}$ ) from the Historical run to the RCP4.5 scenario as simulated by the high-resolution models. In (a), the contour interval is 20 -gpm. The bold contours are the 1560 and $1600-\mathrm{gpm}$ isolines

(a) Global SST Change

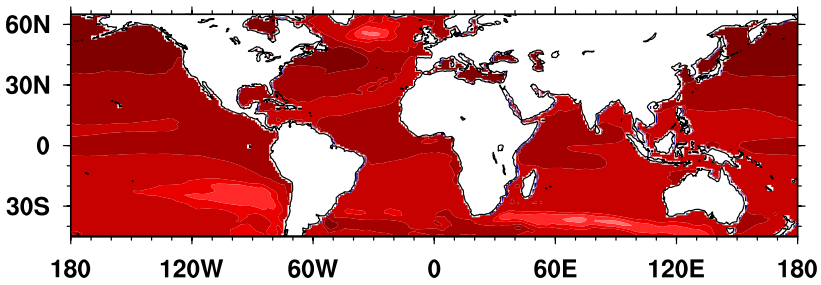

(b) Global SST Change Relative to Global Mean

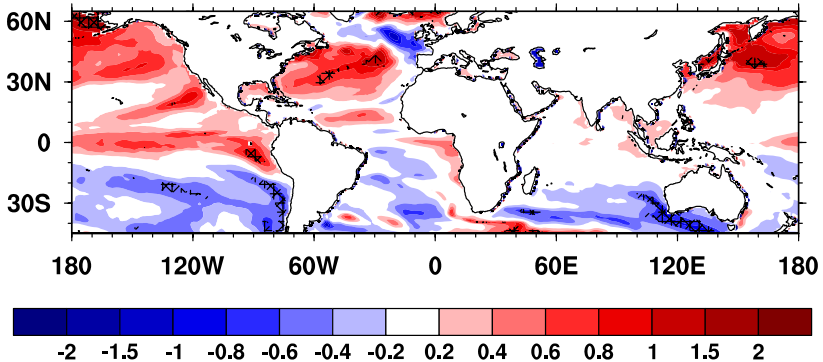

Fig. 8 a Changes in SST from Historical run to RCP 4.5 scenario projected by high-resolution models; b the SST change relative to global mean SST change (shaded, unit: K). The hatched areas in (b) are where the SST changes are significant at $\alpha=0.05$ level

acts to weaken the NASH circulation (Kushnir et al. 2002; Hu and Huang 2006).

The importance of the NASH to future precipitation change over Ethiopia might be further amplified by the conflicting contributions of the EALLJ and TEJ to precipitation change. On the one hand, the high-resolution models project an intensification of the EALLJ in the future (Fig. 9a). The intensification of the EALLJ favors excessive 

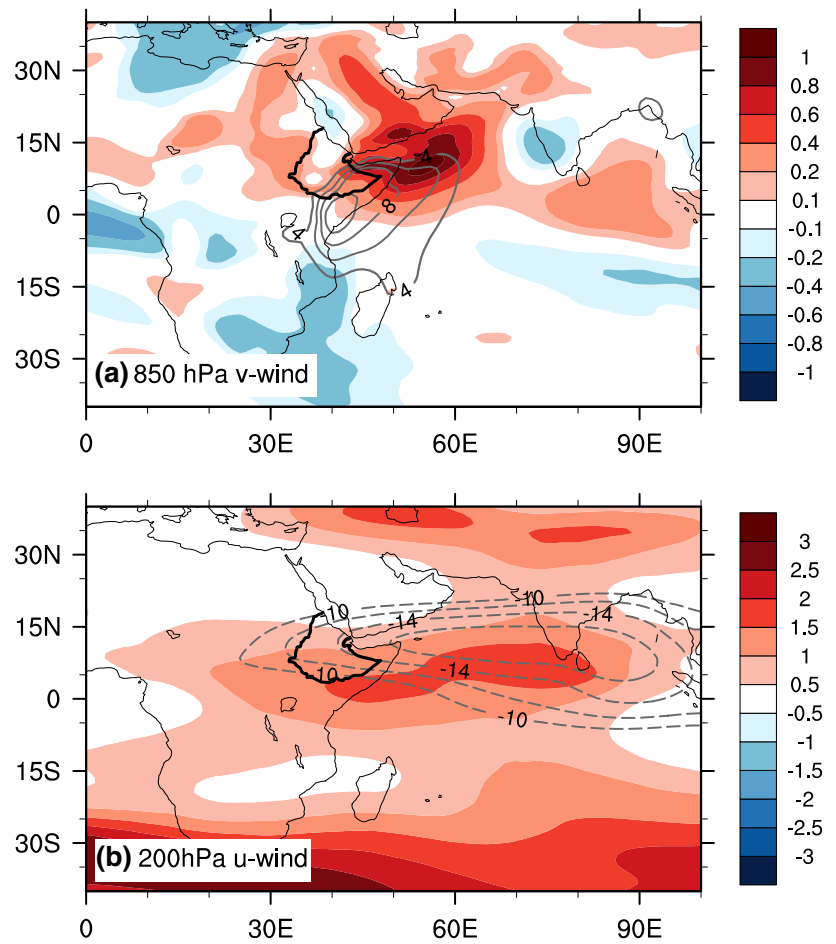

Fig. 9 Changes in (a) $850 \mathrm{hPa}$ meridional (v-component) wind and b $200 \mathrm{hPa}$ zonal (u-component) wind from the Historical (1950-1999) to the RCP 4.5 scenario (2050-2099), according to the projection by the ensemble of 14 high-resolution models (shaded, unit: $\mathrm{m} \mathrm{s}^{-1}$ ). The solid contours in (a) denote the high-resolution model simulated EALLJ in the Historical run (1950-1999 climatology, unit: $\mathrm{m} \mathrm{s}^{-1}$ ), while the dashed contours in (b) denote the simulated 1950-1999 climatology of TEJ (unit: $\mathrm{m} \mathrm{s}^{-1}$ )

precipitation over all of the Ethiopia. On the other hand, the high-resolution models project weakening of the TEJ (Fig. 9b), which tends to decrease precipitation over the entire country (Fig. 6b). The offsetting effects of the EALLJ and TEJ therefore appear to cancel each other out. As a result, future changes in precipitation mainly reflect the influence of the NASH circulation, with a wetting in the northern Rift Valley and drying elsewhere.

\section{Conclusions and discussions}

Kiremt-season precipitation represents a primary water source for Ethiopia's rain-fed agriculture, which is critical to the country's economy and to the livelihoods of the majority of Ethiopians. It is therefore of great importance to better understand potential future changes in precipitation as a result of climate change in order to devise appropriate adaptation strategies.

In this study, the impact of future climate change on Kiremt-season precipitation was assessed using state-ofthe-art CMIP5 GCMs. Model evaluation suggests that horizontal resolution is a critical factor in simulating Ethiopian Kiremt-season precipitation. Compared to observations, high-resolution models (horizontal resolution $<2^{\circ}$ ) reasonably simulate the spatial pattern and domain-averaged precipitation rates over Ethiopia. In contrast, lowresolution models generally underestimate Kiremt-season precipitation, especially over the Great Rift Valley. The improved performance of high-resolution models might be attributable to their capability in representing the topographic forcing and associated processes on precipitation (Slingo et al. 2005).

Overall, the high-resolution models project no significant changes in area-averaged precipitation under the RCP4.5 scenario (2050-2099). However, this weak response in area-averaged precipitation masks important spatial patterns of precipitation change. According to the ensemble of high-resolution models, future precipitation tends to increase over the Central Highlands and northern Great Rift Valley while decreasing over the southern part of the country, presenting a dipole pattern.

This dipole pattern is consistent with the precipitation change caused by an intensification of the NASH circulation in a warming climate. Analysis of high-resolution CMIP5 models suggests that the $850 \mathrm{hPa}$ geopotential height (streamfunction) in the NASH center is expected to increase by more than 15 geopotential meters $\left(3 \times 10^{5} \mathrm{~m}^{2} \mathrm{~s}^{-2}\right)$ during the second half of the twenty-first century. This intensification of the high pressure concurs with an enhancement of upward motion in the northern Great Rift Valley region and a decrease in upward motion to the south, in consistent with the typical patterns associated with an anomalously strong $\mathrm{NASH}$, leading to the model projected dipole pattern in precipitation change.

Analysis of the other two circulation components, the EALLJ and TEJ, indicates that EALLJ tends to intensify in the future while TEJ tends to be weakened. The opposite changes in EALLJ and TEJ cancel out their effects on Ethiopian Kiremt-season precipitation. Consequently, an intensification of the NASH circulation appears to be a primary contributor to future changes in Ethiopian precipitation as the climate warms.

Acknowledgments We acknowledge the World Climate Research Programme's Working Group on Coupled Modeling, which is responsible for CMIP, and we thank the climate modeling groups (listed in Table 1 of this paper) for producing and making available their model output. For CMIP, the U.S. Department of Energy's Program for Climate Model Diagnosis and Intercomparison provides coordinating support and led development of software infrastructure in partnership with the Global Organization for Earth System Science Portals. Part of the CMIP5 model output analyzed in this study is provided by the WHOI CMIP5 Community Storage Server, Woods Hole Oceanographic Institution, Woods Hole, MA, USA from their 
website at http://cmip5.whoi.edu/. The authors thank Dr. Brant Liebmann and another two anonymous reviewers for insightful comments. This work is supported by the NSF Grant AGS-1147608 and NIH1R21AG044294-01A1. The group also benefited from pilot support from the Provost's Office at Duke University and an interdisciplinary collaboration of social and natural scientists working on water and climate change issues at Duke. L. Li is partially supported by the Postdoctoral Scholar Program at the Woods Hole Oceanographic Institution, with funding provided by the Ocean and Climate Change Institute.

\section{References}

Bell JL, Sloan LC, Snyder MA (2004) Regional changes in extreme climatic events: a future climate scenario. J Clim 17:81-87

Chen M, Xie P, Janowiak JE, Arkin PA (2002) Global land precipitation: a 50-yr monthly analysis based on gauge observations. J Hydrometeorol 3:249-266

CIA (2014) The World Factbook: Ethiopia. US Central Intelligence Agency, Washington, USA

Diro GT, Grimes DIF, Black E (2011a) Teleconnections between Ethiopian summer rainfall and sea surface temperature: part Iobservation and modelling. Clim Dyn 37:103-119

Diro GT, Grimes DIF, Black E (2011b) Large scale features affecting Ethiopian rainfall. In: Williams CJR, Kniveton DR (eds) African Climate and Climate Change. Springer, Berlin, pp 13-50

Evangelista P, Young N, Burnett J (2013) How will climate change spatially affect agriculture production in Ethiopia? Case studies of important cereal crops. Clim Change 119:855-873

Feser F, Rockel B, Storch HV, Winterfeldt JRG, Zahn M (2011) Regional climate models add value to global model data. Bull Am Meteorol Soc 92:1181-1192

Gissila T, Black E, Grimes DIF, Slingo JM (2004) Seasonal forecasting of the Ethiopian summer rains. Int $\mathrm{J}$ Climatol 24:1345-1358

Harris I, Jones PD, Osborn TJ, Lister DH (2014) Updated high-resolution grids of monthly climatic observations-the CRU TS3. 10 Dataset. Int J Climatol 34:623-642

Holton JR (ed) (2004) An introduction to dynamic meteorology, vol 48. Academic Press, New York

Hu Z-Z, Huang B (2006) Air-sea coupling in the North Atlantic during summer. Clim Dyn 26:441-457

Hulme M, Tosdevin N (1989) The tropical easterly jet and Sudan rainfall: a review. Theor Appl Climatol 39:179-187

Joly M, Voldoire A, Douville H, Terray P, Royer J-F (2007) African monsoon teleconnections with tropical SSTs: validation and evolution in a set of IPCC4 simulations. Clim Dyn 29:1-20

Kalnay E et al (1996) The NCEP-NCAR 40-year reanalysis project. Bull Am Meteorol Soc 77:437-471

Korecha D, Barnston AG (2007) Predictability of June-September rainfall in Ethiopia. Mon Weather Rev 135:628-650

Kushnir Y, Robinson WA, Bladé I, Hall NMJ, Peng S, Sutton R (2002) Atmospheric GCM response to extratropical SST anomalies: synthesis and evaluation. J Clim 15:2233-2256

Kushnir Y, Seager R, Ting M, Naik N, Nakamura J (2010) Mechanisms of tropical Atlantic SST influence on North American precipitation variability. J Clim 23:5610-5628

Li W, Fu R, Juarez RIN, Fernandes K (2008) Observed change of the standardized precipitation index, its potential cause and implications to future climate in the Amazon region. Philos Trans R Soc B: Biol Sci 363:1767-1772

Li W, Li L, Fu R, Deng Y, Wang H (2011) Changes to the North Atlantic subtropical high and its role in the intensification of summer rainfall variability in the southeastern United States. J Clim 24:1499-1506

Li W, Li L, Ting M, Liu Y (2012) Intensification of Northern Hemisphere subtropical highs in a warming climate. Nat Geosci 5:830-834

Li L, Li W, Deng Y (2013) Summer rainfall variability over the Southeastern United States in the 21st century as assessed by the CMIP5 models. J Geophys Res Atmos 118:340-354

Megersa B, Markemann A, Angassa A, Ogutu JO, Piepho H-P, Zaráte AV (2014) Impacts of climate change and variability on cattle production in southern Ethiopia: perceptions and empirical evidence. Agric Syst 130:23-34

Moss RH et al (2010) The next generation of scenarios for climate change research and assessment. Nature 463:747-756

Nicholson SE, Grist JP (2003) The seasonal evolution of the atmospheric circulation over West Africa and equatorial Africa. J Clim 16:1013-1030

Nicholson SE, Kim J (1997) The relationship of the El Nino-Southern oscillation to African rainfall. Int J Climatol 17:117-135

Otieno VO, Anyah RO (2013) CMIP5 simulated climate conditions of the Greater Horn of Africa (GHA). Part 1: contemporary climate. Clim Dyn 41:2081-2097

Pielke RAS (2002) Mesoscale meteorological modeling, 2nd edn. Elsevier, Amsterdam

Rodríguez-Fonseca B et al (2015) Variability and predictability of West African droughts: a review of the role of sea surface temperature anomalies. J Clim (in press) doi:10.1175/ JCLI-D-1114-00130.00131

Rowell DP (2003) The impact of Mediterranean SSTs on the Sahelian rainfall season. J Clim 16:849-862

Rudolf B, Becker A, Schneider U, Meyer-Christoffer A, Ziese M (2010) GPCC status report December 2010 (on the most recent gridded global data set issued in fall 2010 by the Global Precipitation Climatology Centre (GPCC))

Segele ZT, Lamb PJ (2005) Characterization and variability of Kiremt rainy season over Ethiopia. Meteorol Atmos Phys 89:153-180

Segele ZT, Lamb PJ, Leslie LM (2009a) Seasonal-to-interannual variability of Ethiopia/Horn of Africa Monsoon. Part I: associations of Wavelet-Filtered Large-Scale atmospheric circulation and global sea surface temperature. J Clim 22:3396-3421

Segele ZT, Lamb PJ, Leslie LM (2009b) Large-scale atmospheric circulation and global sea surface temperature associations with Horn of Africa June-September rainfall. Int J Climatol 29:1075-1100

Segele ZT, Richman MB, Leslie LM, Lamb PJ (2015) Seasonal-tointerannual variability of ethiopia/horn of Africa monsoon. Part II: statistical multi-model ensemble rainfall predictions. J Clim (in press)

Shanahan TM et al (2009) Atlantic forcing of persistent drought in West Africa. Science 324:377-380

Slingo J, Spencer H, Hoskins B, Berrisford P, Black E (2005) The meteorology of the Western Indian Ocean, and the influence of the East African Highlands. Phil Trans R Soc A 363:25-42

Taylor KE, Stouffer RJ, Meehl GA (2009) A summary of the CMIP5 experimental design. http://cmip-pcmdi.llnl.gov/cmip5/docs/ Taylor_CMIP5_design.pdf

Taylor KE, Stouffer RJ, Meehl GA (2012) An overview of CMIP5 and the experiment design. Bull Am Meteorol Soc 93:485-498

Tefera A (2012) Ethiopia: grain and feed annual report. Global Agricultural Information Network. USDA Foreign Agriculture Service, Report Number ET 1201

Thornton PK, Jones PG, Alagarswamy G, Andresen J, Herrero M (2010) Adapting to climate change: agricultural system and household impacts in East Africa. Agric Syst 103:73-82 
Ummenhofer CC, Gupta AS, England MH, Reason CJC (2009) Contributions of Indian Ocean sea surface temperatures to enhanced East African rainfall. J Clim 22:993-1013

Viste E, Sorteberg A (2013) The effect of moisture transport variability on Ethiopian summer precipitation. Int $\mathrm{J}$ Climatol 33:3106-3123
World Bank (2008) Ethiopia: Managing water resources to maximize sustainable growth: Country Water Resources Assistance Strategy. Washington, USA, World Bank

Wu L et al (2012) Enhanced warming over the global subtropical western boundary currents. Nat Clim Change 2:161-166 